\title{
Atomistic Monte Carlo Simulations in Steelmaking: High Temperature Carburization and Decarburization of Molten Steel
}

\author{
R. Khanna, R. Mahjoub and V. Sahajwalla \\ Centre for Sustainable Materials Research and Technology, \\ School of Materials Science and Engineering, University of New South Wales, \\ Sydney, NSW2052, \\ Australia
}

\section{Introduction}

Carbon is one of the most important alloying elements in steel; a number of different properties have been attributed to strong interactions between interstitial carbon atoms and defects such as vacancies, dislocations and grain boundaries. The dissolution of carbonaceous materials such as graphite, coal, coke, chars etc. into molten iron is a key step in a range of ironmaking processes (Keogh et al., 1991; Cusack et al., 1991). While there have been some studies on the dissolution behavior of cokes and coal (Orsten \& Oeters, 1988; Wright \& Taylor, 1993; Mourao et al., 1993; Sahajwalla et al., 1994), most of the investigations have focused their attention on the dissolution behavior of graphite (Coller et al., 1994; Kosaka \& Minowa, 1968; Ericsson \& Melberg, 1981; Grigoryan \& Karshin, 1972; Olivares, 1997). These studies both experimental and theoretical have provided a great deal of information about the reaction kinetics and various factors affecting the graphite dissolution rate, and have generally concluded that the dissolution of graphite is governed by mass transfer in the melt. This implies that the reactions at the interface are much faster than mass transfer and therefore do not control the dissolution kinetics. The dissolution behavior of coals, added either as lumps or fines, on the other hand is highly complex and involves volatile reactions and possible particle breakup. An understanding of the processes occurring at the carbon/melt interface is therefore of crucial importance; a fundamental understanding of the interfacial region is presently far from complete.

In addition to carburization from carbonaceous materials, liquid steel can pick up small quantities of carbon from carbon-based refractories, which are expended in the areas of hot metal treatment and transport, steelmaking vessels, steel secondary treatment as well as continuous casting (Sasai \& Mizukami, 1995; Schei et al., 1988; Chen et al., 2000). In ironmaking processes including the Blast furnace and direct ironmaking technologies, significant quantities of carbon are used for the reduction of oxide iron ore as well as for the carburization of reduced metallic iron. High rates of carbon dissolution are generally required for high process efficiency. However during the final stages of refining of steel just prior to its casting into finished products, the composition of steel and relative concentrations of alloying elements are carefully controlled. The pick up of carbon from 
refractories at this stage is highly undesirable both for steel as well as for the refractory, and needs to be minimised.

Another important aspect in steelmaking is on the role played by free surfaces and by surface-active elements (such as sulphur) on the decarburization of molten steel. During decarburization of continuously carbon-saturated liquid iron by $\mathrm{CO}_{2}$ between $1280^{\circ} \mathrm{C}$ and $1600^{\circ} \mathrm{C}$, the presence of small amounts of sulphur (0.01 to $\left.1 \mathrm{wt} \%\right)$ was found to significantly slow down the decarburization rate (Sain \& Belton, 1978). Sulphur was assumed to cover the top monolayer of the liquid surface. Experiments showed a residual rate of decarburization, which was explained by assuming a fraction of sites, that could never be blocked by the surface active sulphur. The interfacial chemical rate was found to be independent of carbon levels for concentrations ranging between $1 \mathrm{wt} \%$ and saturation levels, and was of the first order with respect to the pressure of $\mathrm{CO}_{2}$ gas. The residual rate was also speculated as being either due to atomic misfit or the penetration of the adsorbed layer by the oxidant with a favourable orientation (Sain \& Belton, 1976).

Due to immense technological importance of carburization and decarburization of molten iron for ironmaking \& steelmaking operations, and with $C$ and $S$ playing key roles, our group at UNSW has been working in this field for the past twelve years. We have developed and optimised computer models of Fe-C-S and $\mathrm{Al}_{2} \mathrm{O}_{3}-\mathrm{C} / \mathrm{Fe}$ systems for a fundamental atomic level understanding of high temperature processes taking place in molten iron and its interfaces with solid carbon and with alumina-carbon refractories. These atomic level investigations on a variety of steelmaking phenomena form the focus of this article.

This article is organised as follows. In Section 2, we present details of the atomic model of the Fe-C-S system, various interaction parameters and procedures used for their optimisation and validation for Monte Carlo computer simulations. Sections 3 to 5 respectively present atomistic simulations on the dissolution of carbon from graphite into molten iron, the depletion of carbon from $\mathrm{Al}_{2} \mathrm{O}_{3}-\mathrm{C}$ refractory by liquid steel and the role of free surfaces and surface active species on surface decarburization. All these sections also include specific details of computational algorithms, key results and comparisons with experimental results \& novel findings. Section 6 will summarise key conclusions and ongoing/future research in this field.

\section{Atomic model of $\mathrm{Fe}-\mathrm{C}-\mathrm{S}$ system and various interaction parameters}

\subsection{Fe-C System}

In an attempt to understand atomic level interactions taking place at the graphite/Fe-C interface, we developed a theoretical model of the melt and the interfacial region designed specifically for lattice gas Monte Carlo simulation studies (Khanna \& Sahajwalla, 1999). The main assumption of this model was regarding the structure of the liquid phase. While modeling of a liquid phase without access to direct experimental information, a generally good starting point is various crystalline structures observed for the alloy. There have been a few studies of the $\mathrm{Fe}-\mathrm{C}$ solution phase where the atoms were assumed to occupy rigid lattice sites. In the interstitial model (Van Vlack, 1989), carbon atoms occupied octahedral interstitial sites with Fe atoms arranged on a regular fcc lattice; Monte Carlo simulations of the $\alpha / \gamma$ phase boundary have been reported in literature using this model. A two sub-lattice model using defects and an associated solution model postulating molecular-like aggregates has also been used with varying degrees of success in binary systems containing liquid $\mathrm{Fe}$ (Guillermet et al., 1981; Jordan, 1979). 
While considering the graphite/Fe-C melt interface in our investigation, atoms in molten iron were arranged on a rigid hexagonal lattice (space group: $\mathrm{P}_{3} / \mathrm{mmc}$ ). The sites in the melt were occupied by Fe and $\mathrm{C}$ atoms distributed randomly. This was a key assumption of this model. Although Fe and $\mathrm{C}$ atoms in a molten state are not expected to have a well defined structure, lattice sites need to be pre-defined for lattice gas Monte Carlo simulations. For ease of operation, atoms in $\mathrm{Fe}-\mathrm{C}$ melt were placed on a rigid hexagonal lattice; there were no vacant sites and the contact surface between graphite and $\mathrm{Fe}-\mathrm{C}$ melt was assumed to be smooth. A cubic structure of the melt would have caused unnecessary complications of boundary mismatch across the graphite/liquid iron interface. An attempt was made to account for the liquid nature of $\mathrm{Fe}-\mathrm{C}$ through isotropic pair-wise short-range interaction parameters between the atoms; atomic interactions were however anisotropic in solid graphite.

The range of interaction was restricted to nearest neighbors (nn) in the basal plane and next nearest neighbors (nnn) along the $\mathrm{c}$ direction. The $\mathrm{nn}$ interaction, labeled as $\mathrm{J}_{1}$, accounted for the bonding in the basal plane. The interaction between the nearest neighbors along $\mathrm{c}$ direction, labeled as $\mathrm{J}_{2}$, accounted for the inter-layer bonding. The interactions were anisotropic for solid graphite with $\mathrm{J}_{2}<<\mathrm{J}_{1}$. Isotropic interactions in the liquid Fe-C phase yielded $\mathrm{J}_{1}=\mathrm{J}_{2}$. While studying the ordering behavior of a disordered binary (AB) alloy (Mori et. al., 1963), interactions $\mathrm{J}_{1}\left(\& \mathrm{~J}_{2}\right)$ can be replaced by a single ordering parameter: $\mathrm{J}=$ $\left(\mathrm{J}_{\mathrm{AA}}+\mathrm{J}_{\mathrm{BB}}-2 \mathrm{~J}_{\mathrm{AB}}\right) / 4$. This simplification, however, is not possible in the present case and each interaction has to be taken into account explicitly.

Due to graphite being a solid at the temperatures of interest (up to $1600^{\circ} \mathrm{C}$ ), both $\mathrm{J}_{1}$ and $\mathrm{J}_{2}$ were chosen to be attractive for $\mathrm{C}-\mathrm{C}$ pairs; net bonding needs to be attractive to hold the atoms together. The parameter $\mathrm{J}_{1}$ (and $\mathrm{J}_{2}$ ) was chosen to be repulsive for Fe-Fe pairs in the melt. The saturation concentration of $\mathrm{C}$ in Fe-C melts ranges from 4 to $6 \mathrm{wt} \%$ at a range of steelmaking temperatures (Chipman, 1972). Any additional $C$ is known to precipitate out of the melt which implies a clustering of $\mathrm{C}$ atoms. From ordering energy considerations, the $\mathrm{Fe}-\mathrm{C}$ interaction needs to be repulsive in nature for $\mathrm{C}-\mathrm{C}$ clustering to take place. An attractive $\mathrm{Fe}-\mathrm{C}$ interaction will lead to a disordered system representing a homogenous solution. While the sign of Fe-C interaction could be broadly determined by its ordering behavior, its magnitude depends on the enthalpy of mixing of $\mathrm{Fe}$ and $\mathrm{C}$ and also on the Gibbs energy of graphite (Lakaze \& Sundman, 1991). The cohesive energy of graphite also determines the strength of C-C interaction. Other interaction parameters were represented in units of the nearest neighbor $\mathrm{C}-\mathrm{C}$ interaction strength. Representing atoms as magnetic spins ( $S=+1$ (up) for carbon and $S=-1$ (down) for iron), the Hamiltonian $E$ of the system can be written as

$$
E=-\sum_{i \neq j}^{n n} J_{1}(a-\beta) S_{i}^{a} S_{j}^{\beta}-\sum_{i \neq j}^{n n n} J_{2}(a-\beta) S_{i}^{a} S_{j}^{\beta}-H \sum_{i} S_{i}
$$

where spin $S_{i}{ }^{\alpha}$ represents the type of atom $(\alpha)$ occupying the site $i$ and $J$ 's are the various interaction parameters. Simulations were carried out using the following set of interaction parameters: $J_{1}(C-C)=\mathrm{J} ; \quad J_{2}(C-C)=\gamma J_{1}(C-C) ; \quad J_{1}(F e-F e)=-\mathrm{J} ; J_{2}(F e-F e)=J_{1}(F e-F e) ; J_{1}(F e-C)$ $=J_{2}(F e-C) \cdot \gamma$ was varied in the range $0.05-0.2$ and $J_{1}(F e-C)$ was varied in the range $0.4 \mathrm{~J}$ to $0.7 \mathrm{~J}$. The parameter $\mathrm{J}$ has units of energy and is assumed to be positive in magnitude.

Simulations were carried out in the grand canonical ensemble. A collection of $\mathrm{N}$ spins was placed on a hexagonal lattice; the relative concentration of up and down spins was controlled 
by the carbon content in the melt. The magnetic field $H$ in Eq. (1) was held constant and the relative concentration of spins was allowed to fluctuate. Starting from an initial configuration, a spin was chosen randomly and was flipped $\left(S_{i} \rightarrow-S_{i}\right)$. The energy difference $\Delta \mathrm{E}$ resulting from the spin flip was calculated. The flipping of spin was accepted for $\Delta \mathrm{E} \leq 0$. For $\Delta \mathrm{E}>0$, the change may be accepted with a transition probability $W$ (Binder et al., 1981)

$$
W=\exp \left(-\Delta E / k_{B} T\right) /\left[1+\exp \left(-\Delta E / k_{B} T\right)\right]
$$

where $k_{B}$ is the Boltzmann constant and $T$ the temperature. $W$ was compared to a random number $\eta$ chosen uniformly between 0 and 1 . The move was accepted for $W>\eta$; otherwise old configuration was counted once more for averaging. This algorithm leads to a thermal equilibrium distribution in the limit when the number of generated states tend to infinity. In practice, fairly accurate results can be achieved with few thousand Monte Carlo steps per site. Lattice sizes for simulation ranged between $24 \times 24 \times 24$ to $30 \times 30 \times 30$; typically $10^{6}$ to $10^{8}$ MC steps were used in each simulation. A dimensionless parameter, $T^{*}\left(=k_{B} T / J\right)$ was used to represent reduced temperature.

A very well defined first order phase transition was observed between graphite on the carbon rich end and an ordered solution of $\mathrm{Fe}-\mathrm{C}$ on the low carbon end. The transition was very sharp for $\mathrm{J}_{1}(\mathrm{Fe}-\mathrm{C})=0.6 \mathrm{~J}$ and $0.7 \mathrm{~J}$ and was somewhat broad for $\mathrm{J}_{1}(\mathrm{Fe}-\mathrm{C})=0.4 \mathrm{~J}$ and $0.5 \mathrm{~J}$. A discontinuous behavior was observed in the plots of energy and order parameters. This phase transition was also investigated for the magnitude of $\gamma$ ranging between 0.05 to 0.2 ; the transition became slightly broader with increasing $\gamma$. Apart from causing a general shift, the magnitudes of $\mathrm{C}-\mathrm{C}$ and Fe-Fe interaction parameters did not show any new features. The simulated results compared very well with the experimental phase boundary (Chipman, 1972) and a correspondence was established between the experiment and theory. For example, an experimental study at $1400^{\circ} \mathrm{C}$ corresponded to a carbon solubility limit of $4.88 \mathrm{wt} \%$. For $J_{1}(\mathrm{C}-\mathrm{Fe})=0.5 \mathrm{~J}$ and $0.6 \mathrm{~J}$, this corresponded to $T^{*}=0.465$ and 0.667 respectively. The corresponding $T^{*}$ values for $1600{ }^{\circ} \mathrm{C}$ were 0.503 and 0.717 respectively. The magnitude of $J_{1}(\mathrm{Fe}-\mathrm{C})$ could be chosen either as $0.5 \mathrm{~J}$ or $0.6 \mathrm{~J}$ without any loss of generality. The following sets of interaction parameters were used for dissolution studies: $J_{1}(C-C)=\mathrm{J}$, $J_{2}(C-C)=\gamma \mathrm{J} ; J_{1}(F e-F e)=J_{2}(F e-F e)=-\mathrm{J} ; J_{1}(C-F e)=J_{2}(C-F e)=0.5 \mathrm{~J}$ and $\gamma=0.02$.

\subsection{Fe-C-S System}

The effect of sulphur on the solubility of graphite in iron melts was investigated in the temperature range $1400-1600^{\circ} \mathrm{C}$ based on the atomistic model of Fe-C system. It is well known that $\mathrm{C}$ and $\mathrm{S}$ atoms are strongly repulsive in the Fe-C-S system, and $\mathrm{S}$ atoms also repel each other (Ohtani \& Nishizawa, 1986). The attractive bond between Fe and $S$ is very strong and is more or less ionic in nature. This strong Fe-S bond is capable of distorting the electron distribution around the Fe atom also affect other bonds made by it (Kitchener et al., 1948). In the event of such a distortion taking place, the resulting bond energy will be a fraction $(1-\varepsilon)$ of the energy of the bond made in the absence of a Fe-S bond, with $\varepsilon$ ranging between 0 and 1 .

Representing atoms as magnetic spins ( $S=+1$ for carbon, $S=-1$ for iron and $S=0$ for sulphur), the Hamiltonian $E$ of the system in the Ising model can be written as

$$
E=-\sum_{i \neq j}^{n n}\left[J_{1}(a-\beta) S_{i}^{a} S_{j}^{\beta}+K_{i j} R_{1}(a-\beta)\right]-\sum_{i \neq j}^{n n n}\left[J_{2}(a-\beta) S_{i}^{a} S_{j}^{\beta}+K_{i j} R_{2}(a-\beta)\right]-\mathrm{H} \sum_{i} S_{i}
$$


The constant $K_{i j}$ has a value of 1 if either one or both sites $i$ and $j$ are occupied by sulphur and is zero otherwise. Values of $R$ represent interactions of $S$ with other atoms. The coefficient Js and Rs have units of energy. $\mathrm{H}$ is the magnetic field.

Let $J$ represent the magnitude of the nearest-neighbour $\mathrm{C}-\mathrm{C}$ interaction strength. Simulations were carried out using the following set of interaction parameters for sulphur based interactyions: $R_{1}(\mathrm{~S}-\mathrm{S})=R_{2}(\mathrm{~S}-\mathrm{S})=-(0.1$ to 0.5$) J ; R_{1}(\mathrm{~S}-\mathrm{C})=R_{2}(\mathrm{~S}-\mathrm{C})=-(0.1$ to 0.5$) J ; R_{1}(\mathrm{Fe}-$ $S)=R_{2}(\mathrm{Fe}-\mathrm{S})=(0.2$ to 1$) \mathrm{J}$. The bonds made by Fe atoms which have at least one bond with a sulphur atom were modulated by a factor $(1-\varepsilon)$ where $\varepsilon$ takes on three values: $0.0,0.5$ and 1 . Two values of $\gamma(0.02$ and 0.2$)$ were used in these simulations. Detailed simulations on the system showed that the strength of the Fe-C interaction $\left(J_{1}(\mathrm{Fe}-\mathrm{C})=0.5 \mathrm{~J}\right.$ or $\left.0.6 \mathrm{~J}\right)$ did not have much effect on the linear trend of the decreasing carbon solubility with sulphur. It also did not affect the magnitude of the slope to a great extent. The relative strength of interlayer C$\mathrm{C}$ bonding $(\gamma)$ was also not one of the crucial parameters in controlling the effect of sulphur on carbon solubility.

The strength of the strongly attractive Fe-S interaction appeared to be one of the important parameters. At $1400^{\circ} \mathrm{C}$, and with no distortion of electron distribution around Fe atoms $(\varepsilon=0.0)$, the simulated slopes $m$ were closest to the experimental values for $R_{1}(\mathrm{Fe}-\mathrm{S})=0.5 \mathrm{~J}$ with $R_{1}(\mathrm{~S}-\mathrm{S})$ [and $\mathrm{R}_{1}(\mathrm{C}-\mathrm{S})$ ] ranging from $-0.1 \mathrm{~J}$ to $-0.5 \mathrm{~J}$. $R_{1}(\mathrm{Fe}-\mathrm{S})=0.2 \mathrm{~J}$ gave lower values of the slope and $R_{1}(\mathrm{Fe}-\mathrm{S})=1.0 \mathrm{~J}$ gave higher values. Overall slope values were slightly higher at $1600^{\circ} \mathrm{C}$. With the $\mathrm{Fe}-\mathrm{S}$ bond distorting the electron distribution around the Fe atom, either by an intermediate amount $(\varepsilon=0.5)$ or by a large amount $(\varepsilon=1.0)$, the slopes were no longer dependent on the actual magnitude of $R_{1}(\mathrm{Fe}-\mathrm{S})$ and $R_{1}(\mathrm{~S}-\mathrm{S})$ [and $R_{1}(\mathrm{C}-\mathrm{S})$ ] and showed a rather flat range. The variation in slopes was within simulation error bars. The strength of the Fe-S interaction and its effect on the electron distribution around Fe atoms appeared to be one of the most important factors in determining the effect of sulphur on the solubility of graphite in $\mathrm{Fe}-\mathrm{C}-\mathrm{S}$ melts.

We extended this model further with the aim of optimizing various interaction parameters (Sahajwalla \& Khanna, 2002) and to investigate the effect of electronic distortions around Fe and their relative importance in the molten state. Apart from a decrease in carbon solubility, the validated model needed to simultaneously satisfy other well-known features of this system. In the absence of carbon, the Fe-S system can be regarded as a solution of FeS in the iron melt. Even though this solution is non-ideal, it is completely miscible and forms a homogeneous phase. However the addition of small amounts of carbon cause Fe-C-S solution to separate into two immiscible layers, one rich in sulfur but low in carbon and other rich in carbon but low in sulphur (Morris \& Buehl, 1950; Morris \& Williams, 1949).

An atomic model, which can account for these key features of the Fe-C-S system, can be used to identify optimum strengths of various interaction parameters and form the basis for further studies on this system. As $\mathrm{C}$ and $\mathrm{S}$ atoms tended to displace each other to regions of high and low concentrations, it was assumed that this displacement was mediated by an $\mathrm{Fe}$ atom. Treating both $\mathrm{C}$ and $\mathrm{S}$ atoms on an equal footing and assuming electronic distortions around Fe play a significant role in this displacement process, two new parameters ( $\delta$ 's) were defined. $\delta(\mathrm{Fe}-\mathrm{C})$ represents the modification in the $\mathrm{Fe}-\mathrm{C}$ interaction parameter, when the Fe atom has an additional bond with S. Similarly $\delta(\mathrm{Fe}-\mathrm{S})$ represents modification in the $\mathrm{Fe}-\mathrm{S}$ interaction parameter, when the $\mathrm{Fe}$ atom has an additional bond with $\mathrm{C}$. These parameters were varied over a wide range. $\delta(\mathrm{Fe}-\mathrm{S})$ ranged from -0.5 to 1.0 with $\delta$ $(\mathrm{Fe}-\mathrm{C})=1.0$. It was expected that a locally repulsive $\mathrm{Fe}-\mathrm{S}$ interaction may lead to a displacement of $S$ from $C^{\prime}$ s neighbourhood. 
Simulations results on a homogenous Fe-C-S system showed that the liquid separated into two immiscible regions only for $\delta(\mathrm{Fe}-\mathrm{S})=1.0$. This indicates that distortion around Fe did not significantly affect Fe-S interaction strength and could be neglected. This separation was however most pronounced for $\delta(\mathrm{Fe}-\mathrm{C})=1.5$. Phase diagram simulations on carbon solubility also led to similar conclusions. Small values of $\delta(\mathrm{Fe}-\mathrm{S})(-0.5$ and 0.0$)$, which were found unsuitable in miscibility studies, also showed negligible effect of sulfur on carbon solubility. The parameter, $\delta(\mathrm{Fe}-\mathrm{C})=0.5$, was found to be completely unsuitable as it led to a slight increase in solubility rather than a decrease. Optimum parameters for this system, which simultaneously simulate the well known properties of $\mathrm{Fe}-\mathrm{C}-\mathrm{S}$ system were determined as: $\varepsilon(\mathrm{Fe}-\mathrm{Fe})=1.0, \delta(\mathrm{Fe}-\mathrm{S})=1.0, \delta(\mathrm{Fe}-\mathrm{C})=1.0$ and 1.5. Simulation results on the Fe-C-S system clearly showed that distortions around $\mathrm{Fe}$ due to a strong $\mathrm{Fe}-\mathrm{S}$ bond did not play a significant role in the molten state.

\section{Dissolution of carbon into molten iron}

Two identical blocks with hexagonal sites were placed in contact with each other (Fig. 1). All sites on the first block representing solid graphite were occupied by carbon. Sites on the second block representing Fe-C system were occupied by $\mathrm{Fe}, \mathrm{C}$ atoms distributed randomly. The relative concentrations of $\mathrm{Fe}, \mathrm{C}$ and $\mathrm{S}$ atoms were governed by the carbon and sulphur content of the melt under consideration.

\section{Interface}

\begin{tabular}{l|l}
\hline graphite & Fe-C melt \\
& \\
\hline
\end{tabular}

Fig. 1. A schematic representation of the simulation arrangement

The dissolution rate of graphite can be defined in terms of the number of carbon atoms that dissolve in the melt as a function of time. With $N_{c}$ representing the total number of $C$ atoms which have dissociated from the solid and have been transferred into the melt at time $t$ and $N_{t}$ the total number of MC steps, the dissolution rate can be computed throughout the duration of the dissolution process using the following equation:

$$
\frac{d C}{d t}=\frac{N_{c}}{N_{t}}
$$

The computed magnitudes of energy, dissolution rate, interfacial profile and widths depend on a large number of simulation variables, e.g., lattice size, contact area, interaction strengths etc. As simulation time is measured in units of Monte Carlo steps, no attempt was made to compare actual magnitudes of simulation results with the experimental values quoted in literature. Instead, the focus was on identifying various simulation trends. 


\subsection{Interfacial reactions}

Fig. 2 shows a plot of the initial atomic profile of the graphite/Fe-C system across the basal plane. The initial carbon concentrations in the melt were chosen to be $0.0 \mathrm{wt} \%$ and $2 \mathrm{wt} \%$. The layer $Z=80$ indicates the initial boundary between the solid and the melt. Fig. $2 \mathrm{~b}$ shows the atomic distribution after simulation. Fe atoms appeared to have moved by up to 40 layers into graphite. On the other hand, $\mathrm{C}$ atoms moved right up to the melt boundary. The midpoint of $C$ profile in graphite also moved back from $Z=80$ to $Z=55$, indicating significant dissolution of graphite.
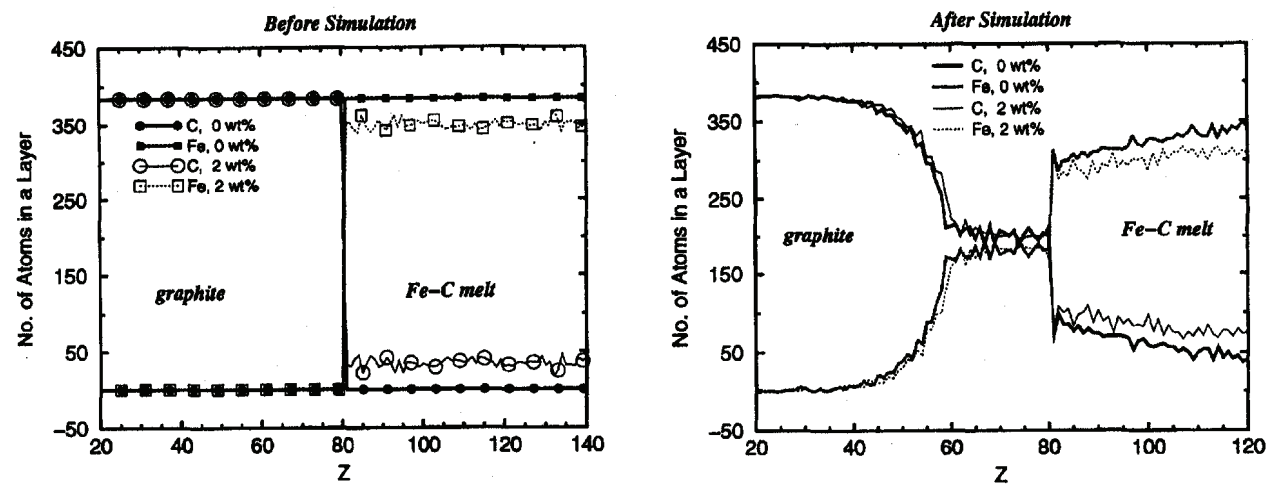

Fig. 2. Atomic distribution profile across graphite/Fe-C interface before and after simulation. $Z$ corresponds to the layer number normal to the interface.

Once a $\mathrm{C}$ atom broke away from graphite, it was found to propagate easily in the melt. Fe atoms, however, found it difficult to penetrate solid graphite. The movement of a $\mathrm{C}$ atom in the melt involved the replacement of a repulsive Fe-Fe bond with a less repulsive Fe-C bond or an attractive $\mathrm{C}-\mathrm{C}$ bond in place of a repulsive $\mathrm{Fe}-\mathrm{C}$ bond. This process lowers the energy of the system and is therefore energetically favorable. On the other hand, the movement of an Fe atom replaces an attractive $\mathrm{C}-\mathrm{C}$ bond with a repulsive $\mathrm{Fe}-\mathrm{C}$ bond, a move not favored energetically. At $T^{*}=0$, there should be no movement of Fe into graphite. On the other hand, a carbon atom once released from the graphitic substrate, can dissolve into the melt at all temperatures. Fig. $2 \mathrm{~b}$ also shows a slight reduction in the width of the interfacial region with increasing carbon content of the melt.

The graphite dissolution rates across the basal plane have been plotted in Fig. 3a as a function of time for temperatures ranging from $1300^{\circ} \mathrm{C}$ to $1600^{\circ} \mathrm{C}$. This plot can be divided in two regions. Region I, showing a sharp increase in dissolution rate, was restricted to a short period in the initial stages of contact between graphite and melt. C-C atom pairs across the basal plane have strong covalent bonds. It costs system energy to break these bonds and to replace them with repulsive $\mathrm{Fe}-\mathrm{C}$ bonds. Once a few of these bonds get broken due to high temperature of the melt, it becomes relatively easier to release additional $\mathrm{C}$ atoms as some of these are now less strongly bound. During this short period, the dissolution rate of graphite is controlled by the slow reactions at the interface $\left(k<K_{m}\right)$.

The dissociation of $C$ picked up after a short time. Increasing temperature also made the dissociation of $\mathrm{C}$ atoms easier and pushed region I to shorter times. In region II, the 
dissolution was controlled by the mass transfer in the melt, which now becomes the slower process $\left(K_{m}<k\right)$. This represents the typical behavior observed in graphite dissolution experiments. The influence of temperature in region I was more significant as compared to region II. Due to generally higher activation energies, chemical reactions are more sensitive to temperature than mass transfer. This result supports the hypothesis that dissolution process is controlled by interfacial reactions in region I and by mass transfer in region II.
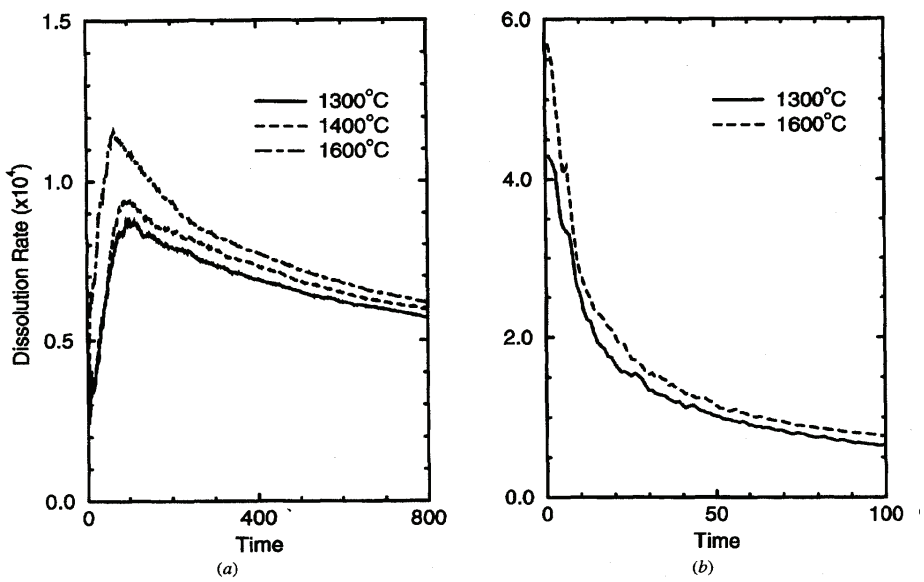

Fig. 3. Carbon dissolution rate as a function of time across (a) the basal plane and (b) the prismatic plane

The dissolution rates across prismatic planes are shown in Fig. 3b. The inter-layer bonding between $\mathrm{C}$ atoms is very weak and $\mathrm{C}$ atoms along this surface are very easily dissociated from graphite. Region I was not observed as there was no hindrance to $C$ dissociation at the interface and the reactions at the interface were quite fast. The dissolution rates, which were much higher in the initial stages, were completely controlled by mass transfer in the melt.

A Monte Carlo simulation study was also carried out on the dissolution of a single graphite particle in $\mathrm{Fe}-\mathrm{C}(0-4 \mathrm{wt} \%)$ melts in the temperature range $1400^{\circ} \mathrm{C}$ to $1600^{\circ} \mathrm{C}$ (Sahajwalla \& Khanna, 2000). Using canonical ensemble, simulations were carried out as a function of particle size, carbon content of the melt and temperature. Simulation results showed that the dissolution of a graphitic particle does not take place layer by layer. The $C$ atoms in the basal plane dissolved preferentially from the edges and iron liquid slowly moved in towards the centre. The atoms on a prismatic plane on the other hand dissolved all across the particle surface. Iron liquid penetrated deep in the particle and led to the formation of a broad interfacial region containing high concentrations of both $C$ and Fe. The overall particle dissolution profile as a function of particle size, temperature and C concentration in the melt showed a good agreement with theoretical and experimental results. Even as carbon dissolution neared completion on a given surface, small islands of graphite could still be seen in a sea of melt.

\subsection{Influence of sulphur}

Initially sulphur atoms were distributed randomly and uniformly in the Fe- $4 \mathrm{Wt} \% \mathrm{~S}$ melt. Atomic distribution profiles for $\mathrm{Fe}, \mathrm{C}$ and $\mathrm{S}$ atoms are plotted in Fig. 4 as number of atoms 
in a given layer before and after simulation. $Z=50$ represents the initial graphite/melt contact surface. When this melt was brought in contact with a block of graphite, various atoms started diffusing across the interface. While $\mathrm{C}$ atoms dissociated from the graphite block and dissolved in the iron melt, some Fe atoms also penetrated the graphite block (Sahajwalla \& Khanna, 1999).
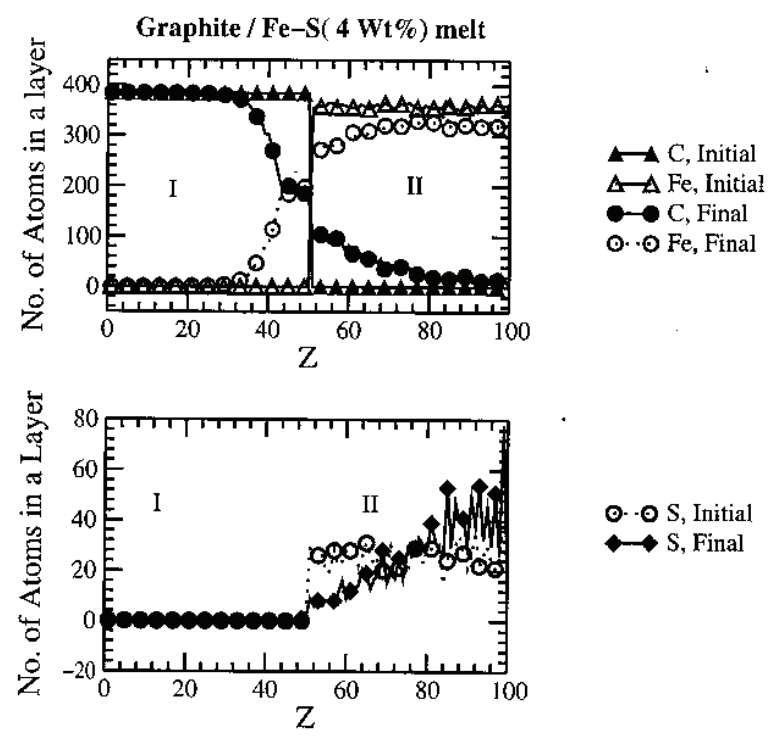

Fig. 4. Atomic distribution profile across graphite/Fe-S interface before and after simulation. $\mathrm{Z}$ corresponds to the layer number normal to the interface.
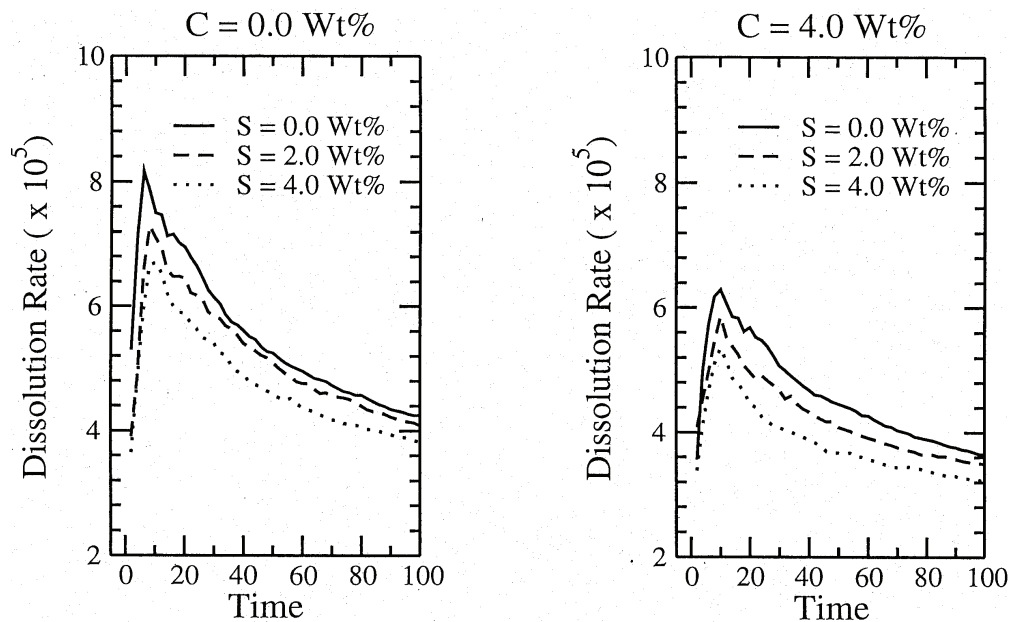

Fig. 5. Carbon dissolution rate as a function of time, across basal plane for a range of carbon and sulphur concentrations in the melt. 
However there was no indication of $\mathrm{S}$ atoms penetrating the graphite block or blocking up the interfacial region. Instead these tended to move away from the interface and penetrate deep in the iron melt. This result is in excellent agreement with the EDS results of Wu et al (Wu et al., 2000) as they also did not find any evidence of a sulphur peak in the interfacial region in the initial stages of contact. There appeared to be well-defined regions of high $C$ \& low $S$ close to the interface and low $C \&$ high $S$ deep in the melt.

In Fig. 5, the dissolution rate of graphite is plotted as a function of time for a range of $C$ and $\mathrm{S}$ concentrations of the melt. These results are for the basal plane of graphite in contact with hot melt. Due to strong covalent bonds between $\mathrm{C}$ atoms in the basal plane, dissociation of $\mathrm{C}$ atoms was quite slow and interfacial effects were rate controlling in the initial stages of contact. Dissociation rate picked up after some time and the carbon dissolution rate controlling mechanism changes over to mass transfer in the melt. However the presence of sulphur in the melt appeared to affect both these mechanisms.

The presence of sulphur in the melt affected the overall carbon dissolution rate adversely. This reduction takes place in the initial stages of contact and also when carbon concentration in the melt is close to saturation. In the initial stages of contact when interfacial effects were rate controlling, the presence of $S$ led to a lowered carbon dissociation rate. This decrease was attributed to bond energy considerations and was not due to any interface blockage by sulphur atoms.

\section{Depletion of carbon from $\mathrm{Al}_{2} \mathrm{O}_{3}-\mathrm{C}$ refractories into molten iron}

The atomic model of the graphite-alumina/liquid iron system was developed based on the atomic model of the graphite/liquid Fe-C system. These simulations were focussed on modelling the synthetic graphite-alumina/liquid iron system consistent with experimental observations in the system (Zhao \& Sahajwalla, 2003). A validated atomistic model with optimum interaction parameters could then be used to systematically investigate the effect of various operating conditions such as temperature, melt turbulence, composition, on carbon dissolution and to provide guidelines for developing optimum refractories for steelmaking applications.

A key feature of this model was to include alumina molecules in the solid graphitic lattice. A molecule of alumina was represented as an inert, rigid unified group of five atoms, masking the fine detail regarding aluminum and oxygen constituents. This approach is quite common in computer simulation studies on complex molecules (Allen \& Tildesley, 1987). As the molar volume for alumina $\left(25.575 \mathrm{~cm}^{3}\right)$ is nearly five times the molar volume for graphite $\left(5.298 \mathrm{~cm}^{3}\right)$ (Weast \& Estle, 1982), a molecule of alumina was allocated five neighboring lattice sites as against a single site for a carbon and iron atoms. With iron being in liquid state in this study, the atomic size differences between $\mathrm{C}$ and Fe atoms were neglected.

Two identical blocks of dimensions $\mathrm{L} \times \mathrm{L} \times \mathrm{L}_{\mathrm{d}}$, with hexagonal sites, were placed in contact with each other (Fig. 6). Sites on the first block, representing alumina-graphite refractory were occupied by alumina and carbon distributed randomly. The relative concentrations of alumina and carbon atoms were governed by the refractory composition under consideration. All sites on the second block representing liquid steel were occupied by $\mathrm{Fe}$ atoms. In these studies, the basal plane of graphitic structure was placed in contact with the melt. This plane was preferred over the prismatic plane due to more significant interfacial reactions expected from this surface due to the relatively strong strengths of $\mathrm{C}-\mathrm{C}$ bonds in the basal plane. 


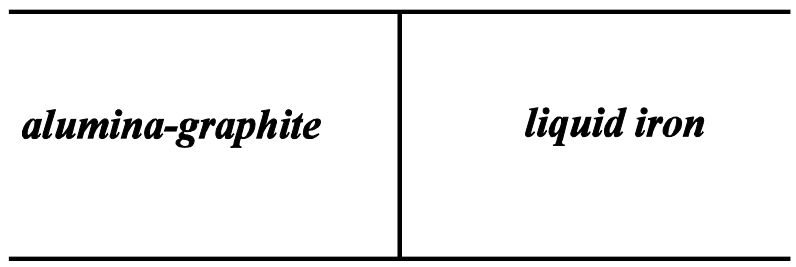

Fig. 6. A schematic representation of the simulation arrangement

The alumina-carbon interactions were assumed to be attractive in nature and the strength of the alumina-carbon interaction was varied over a range in an attempt to simulate the effect of binders commonly present in refractories. The alumina-iron interaction was assumed to be repulsive in nature due to their generally non-wetting behavior. While signs of these interaction parameters were estimated from fundamental considerations, their magnitudes were optimized and determined during these simulations. The interactions were chosen to be isotropic throughout the simulation lattice except for the C-C interactions, which were anisotropic due to weak van der Waals interactions along c-axis.

An attempt was made to incorporate the non-wetting between alumina and graphite through strong but finite repulsion between alumina and iron (Fig. 7a) and also by modifying the nature of interactions on the solid/liquid interface (Fig. $7 \mathrm{~b}$ ). Both approaches proved to be unsuccessful. A third attempt was then made to simulate non-wetting behaviour in terms of mutual exclusion of alumina and iron from their immediate neighbourhood (Fig. 7c). This approach coupled with the immobility of alumina showed a good fit to experimental results on the graphite-alumina/liquid iron system and helped in developing an atomistic model of the system.

In addition, the alumina interaction parameters were found to be redundant, having no effect on simulation results. The optimum interaction parameters for the graphitealumina/liquid iron system were determined as: $J_{1}(C-C)=-J, J_{1}(C-F e)=0.6 J, J_{1}(F e-F e)=J$ and no interaction parameters for alumina. Turbulence in the melt was generated through additional atomic motion on melt sites. Results on the effect of melt turbulence on carbon dissolution from three refractory compositions are shown in Fig. 8a. With increased turbulence, there was an increase in the rate of carbon dissolution in the initial stages of contact for high carbon refractory mixtures $(90 \% \mathrm{C}$ and $70 \% \mathrm{C})$. However there was no significant change in their steady-state carbon content. This result can be understood in terms of increased rates of mass transfer in the melt caused by the melt turbulence leading to an improvement in the overall carbon dissolution rates. Melt turbulence did not have any effect on carbon dissolution from the refractory mixture containing $50 \% \mathrm{C}$.

The effect of temperature on carbon dissolution is shown in Fig. 8b. An increase in temperature from $1400^{\circ} \mathrm{C}$ to $1600^{\circ} \mathrm{C}$ would result in an increase in the transition probability $W$ (Eq. 2) for Monte Carlo steps. While there was no noticeable change observed in carbon dissolution from refractory mixture containing $50 \% \mathrm{C}$, a substantial increase in carbon dissolution was observed for the mixture containing $90 \% \mathrm{C}$. A marginal improvement in carbon dissolution rates was observed for $70 \% \mathrm{C}$. While both temperature and melt turbulence had a significant influence on high carbon systems, these results clearly indicate that for refractory mixtures containing alumina in excess of $50 \%$, carbon depletion from the refractory was not affected by the increased levels of melt turbulence or higher temperatures. 


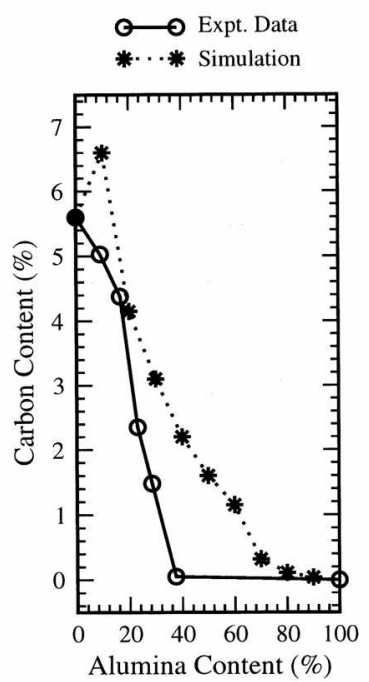

(a)

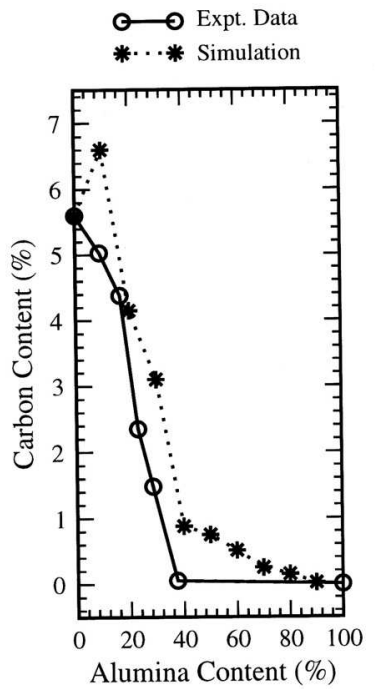

(b)

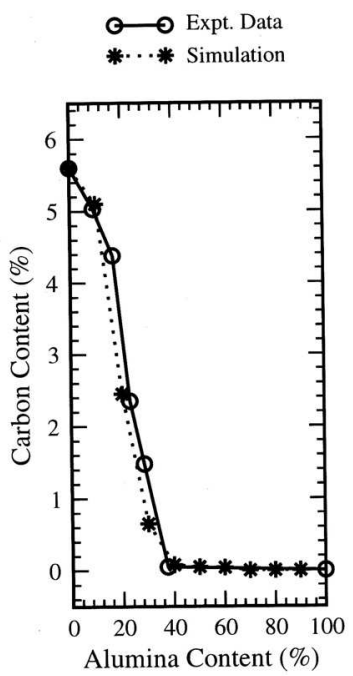

(c)

Fig. 7. Atomistic simulation results on graphite-alumina/liquid steel system. The nonwetting between alumina and liquid iron modelled as (a) strong but finite repulsion, (b) a modification of the nature of interactions on the solid/liquid interface, (c) mutual exclusion of alumina and iron from their immediate neighbourhood.

Effect of turbulence

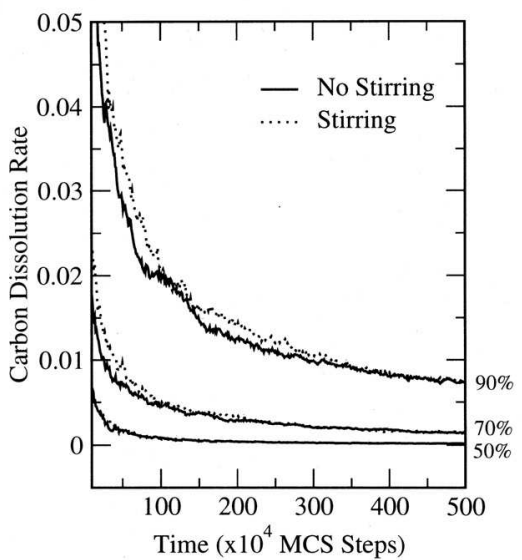

(a)
Effect of temperature

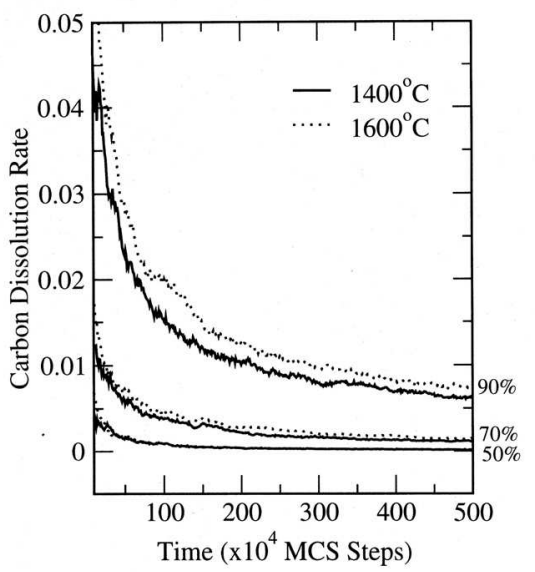

(b)

Fig. 8. Influence of operating parameters (a) the melt turbulence, and (b) temperature on carbon dissolution from three refractory mixtures. Concentrations on the right indicate the initial carbon concentration in the synthetic graphite-alumina refractory mixture. 


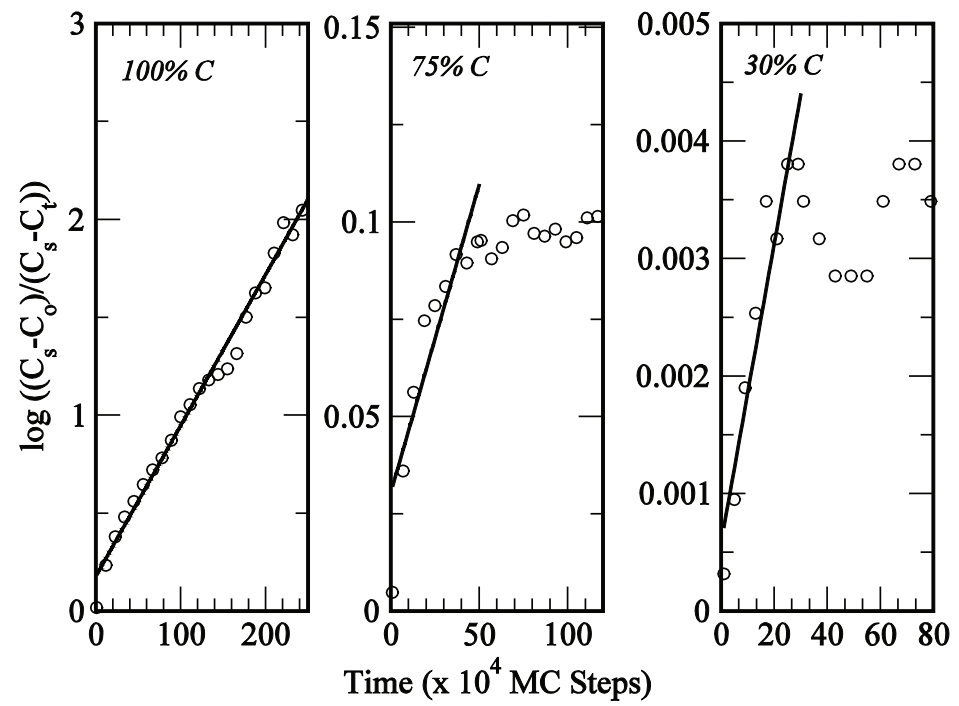

Fig. 9. Simulation results on $\log \left(\left(\mathrm{C}_{\mathrm{s}}-\mathrm{C}_{\mathrm{t}}\right) /\left(\mathrm{C}_{\mathrm{s}}-\mathrm{C}_{\mathrm{o}}\right)\right)$ plots as a function of time for aluminacarbon refractories in contact with liquid iron at $1600^{\circ} \mathrm{C}$.

In Fig. 9, we have plotted $\log \left(\left(C_{s}-C_{t}\right) /\left(C_{s}-C_{o}\right)\right)$ as a function of time for three substrates (Sahajwalla et al., 2006). While a linear trend was observed for synthetic graphite $(100 \% \mathrm{C})$, simulations from refractories containing $75 \% \mathrm{C}$ and $25 \% \mathrm{C}$ respectively did not show a linear correlation between $\log \left(\left(\mathrm{C}_{\mathrm{s}}-\mathrm{C}_{\mathrm{t}}\right) /\left(\mathrm{C}_{\mathrm{s}}-\mathrm{C}_{\mathrm{o}}\right)\right)$ and time. Simulation results indicate that carbon dissolution in refractory mixtures was not governed by a first order kinetic process. Atomistic simulations and experimental results on these three systems have shown similar trends.

These results indicate that mass transfer in the melt was not a dominant rate controlling mechanism for alumina-carbon refractories. Poor wettability of alumina with liquid iron and its significant influence on inhibiting the penetration of liquid iron in the refractory matrix, and consequently a very limited contact between carbon and liquid iron was found to the dominant mechanism through which carbon dissolution from refractories gets strongly suppressed. This study has important implications for a fundamental understanding of refractory behaviour at high temperatures and for further developments in commercial alumina-carbon refractories which use up to $35 \% \mathrm{C}$ in their formulation.

\section{Decarburisation reactions in molten Fe-C-S system: the role of free surfaces}

Carbon levels in steel are controlled carefully through decarburization and refining processes (Mclean, 2006; Sain and Belton, 1978). During decarburization of continuously carbon-saturated liquid iron by $\mathrm{CO}_{2}$ between $1280^{\circ} \mathrm{C}$ and $1600^{\circ} \mathrm{C}$, the presence of small amounts of sulphur (0.01 to $1 \mathrm{wt} \%)$ was found to significantly slow down the decarburization rate (Roddis, 1973). It was also found that during the decarburization of iron melts containing 1-3 wt\% $\mathrm{C}$ and up to $3 \mathrm{wt} \% \mathrm{~S}$ using an $\mathrm{O}_{2}$-Ar mixture, an oxide film was consistently observed on the metal droplet surface. Increasing sulphur contents generally increased the tendency of surface oxide formation under otherwise similar conditions. 
Gao et al (2000) carried out an in-depth investigation on the influence of sulphur content on the carbon boil phenomena and $\mathrm{CO}$ generation in Fe-C-S droplets $(\mathrm{C}=4.2 \mathrm{wt} \%, \mathrm{~S}=0.005-0.4$ $\left.\mathrm{wt} \%, 1370-1450^{\circ} \mathrm{C}\right)$. Carbon boil is known to occur when the internal pressure of $\mathrm{CO}$ gas is high enough to exceed the surface energy of the metal drop. Times for carbon boil were found to range between 5 to 20 seconds; these were independent of sulphur up to a certain level and then decreased with a further increase in the sulphur content. During these decarburization studies, sulphur levels remained fairly unchanged throughout the duration of the experiment.

Existing theories were found to be inadequate in explaining key experimental results on the decarburization of steel, a very important aspect of steelmaking. Using ideal monolayer adsorption isotherms, Sain and Belton (1976) assumed that the surface activity effects of sulphur could to be due to its occupying a majority of the surface sites thereby blocking the reaction. For high sulphur levels in the melt $(\sim 0.02 \mathrm{wt} \% \mathrm{~S})$, these models predicted a complete coverage of the surface with sulphur and zero decarburization of the melt. A fresh look at the influence of sulphur on the kinetics of decarburization reactions was therefore required to develop a better understanding of reaction processes over a range of reaction conditions.

Computer simulations on thin films have reported that surface effects extend up to the top three atomic layers, where the surface characteristics are significantly different from the bulk (Binder et al., 1995; Shpyrko et al., 2005). It is quite likely that the surface of molten steel is multi-layered instead of a monolayer and could include several neighbouring layers close to the liquid surface. If sulphur atoms are present on a number of surface layers instead of the top monolayer, there is a strong likelihood for elements other than sulphur to be present on the surface thereby pointing to additional reaction pathways.

Atomistic computer simulations were carried on molten Fe-C-S system using isotropic atomic interaction parameters; free surfaces were characterised by a missing layer of atoms. Simulations were carried out as a function of melt carbon and sulphur concentration, temperatures and surface/volume ratios of the simulation cell. Monte Carlo simulations based on lattice gas models do not allow continuous motion of atoms; with various atoms occupying rigid lattice sites, complex distance dependent potentials were replaced by appropriate interaction parameters. Simulations were based on the bulk interaction parameters; surface interactions parameters between $\mathrm{Fe}, \mathrm{C}$, and $\mathrm{S}$ atoms were assumed to be identical in magnitude to the corresponding bulk interaction parameters. The simulation cell geometry is schematically shown in Fig. 10.

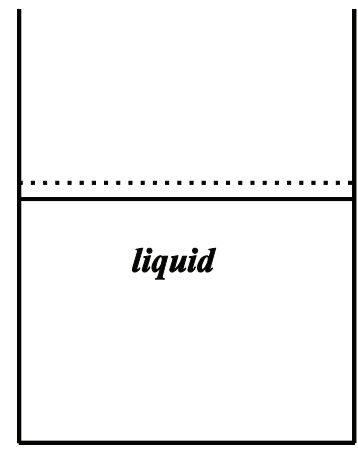

Fig. 10. Molten bath simulation cell configuration; dotted line represents the free liquid surface. 
Turbulence in the liquid at high temperatures allowed a continuous/sporadic movement of atoms within the liquid. Periodic boundary conditions were not used for surface atoms. Another key difference between the surface atoms and those in the bulk was in the form of absent atomic planes/bonds, which could in turn result in major differences in overall interaction energies. The size $\mathrm{L}$ of the simulation cell was chosen to be quite large, ranging from 24 to 36; depth $M$ was chosen to range between 10 and 300 to investigate bath configurations with different surface/volume ratios. The surface to volume ratio (S/V) was computed as a dimensionless number by dividing the number of surface sites by the total number of sites in the simulation cell.

Computer simulations were carried out at $1400^{\circ} \mathrm{C}$ and $1500^{\circ} \mathrm{C}$ for melt carbon contents of 3.2 $\mathrm{wt} \%$ and $4.2 \mathrm{wt} \%$. Sulphur concentration in the melt typically ranged from 0 to $1.5 \mathrm{wt} \%$. Simulation results for the configuration: $24 \times 24 \times 15$ lattice (No. of sites in a layer $=384$ ), C = $4.2 \mathrm{wt} \%, 1500^{\circ} \mathrm{C}$, are shown in Fig. 11 . Sulphur was found to predominantly concentrate in the top few layers with very little sulphur found in the interior bulk. The sulphur concentration was found to be highest in the second layer; this result was observed for all sulphur concentrations under investigation.

\section{$\mathrm{C}=4.2 \mathrm{Wt} \%, 1500^{\circ} \mathrm{C}$}

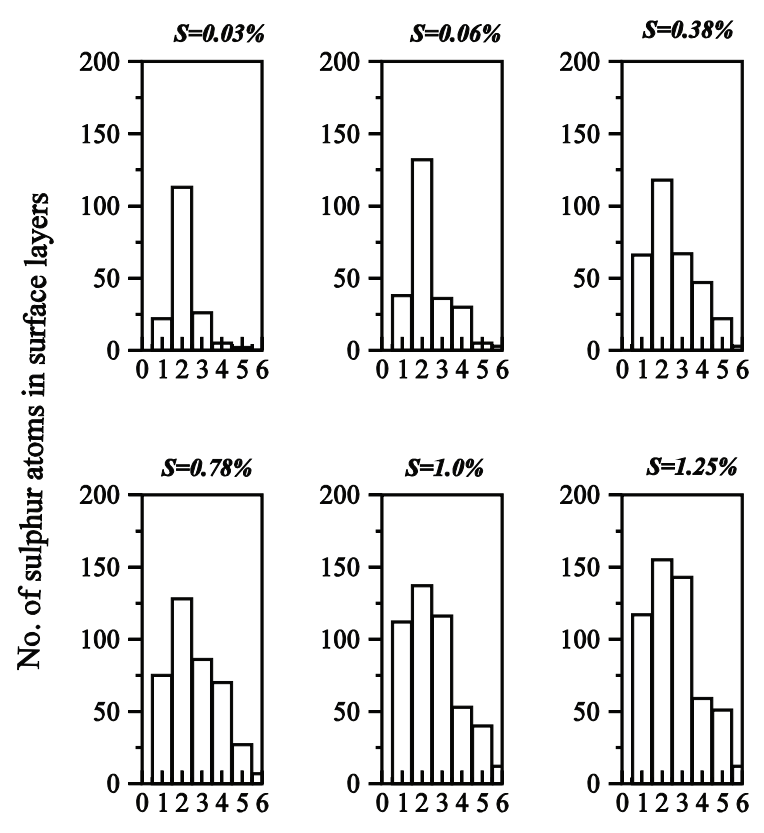

Atomic layers from the surface

Fig. 11. Concentration of sulphur in the top five surface layers in a liquid bath configuration (24x24x15). Results for $\mathrm{C}=4.2 \mathrm{wt} \%, \mathrm{~T}=1500^{\circ} \mathrm{C}$ have been presented. Corresponding bulk sulphur values ranging from $0.03 \%$ to $1.25 \%$ have also been shown above individual bar plots. 
With $1.25 \mathrm{wt} \%$ average sulphur concentration in the bulk melt, $\mathrm{S}$ atoms occupied 118 sites out of the 384 sites available on the top surface layer. This result clearly shows that a complete surface coverage with sulphur does not take place even when the number of available sulphur atoms far exceeds the number of surface sites available. Instead, these are distributed in a 3-5 atomic layer thick surface region leaving plenty of sites available for other atomic species. This trend, which appears to be a fundamental characteristic of the system, was observed for various carbon and sulphur levels, temperatures and bath depths. This finding is significantly different from the monolayer theory for the surface proposed by Sain and Belton (1978).

In Fig. 12 we report on the influence of surface/volume (S/V) ratio on the atomic concentration profiles of sulphur, iron and carbon in the top 5 surface layers. As significant variations in the melt carbon concentration did not have much influence on the sulphur distribution in the surface region, as a representative example we present specific results for an iron melt with $\mathrm{C}=4.2 \mathrm{wt} \%, \mathrm{~T}=1500^{\circ} \mathrm{C}$. Total sulphur concentration in the melt was chosen to be $0.5 \mathrm{wt} \%(0.025$ at. \%). In the liquid bath configuration $(24 \times 24 \times \mathrm{M}), \mathrm{S} / \mathrm{V}$ ratios ranging from 0.0667 to 0.2 were obtained by varying the bath depth $\mathrm{M}$ from 20 to 10 . Most of the sulphur available in the melt was found to concentrate in the surface region; sulphur levels in the bulk liquid were found to be negligibly small.
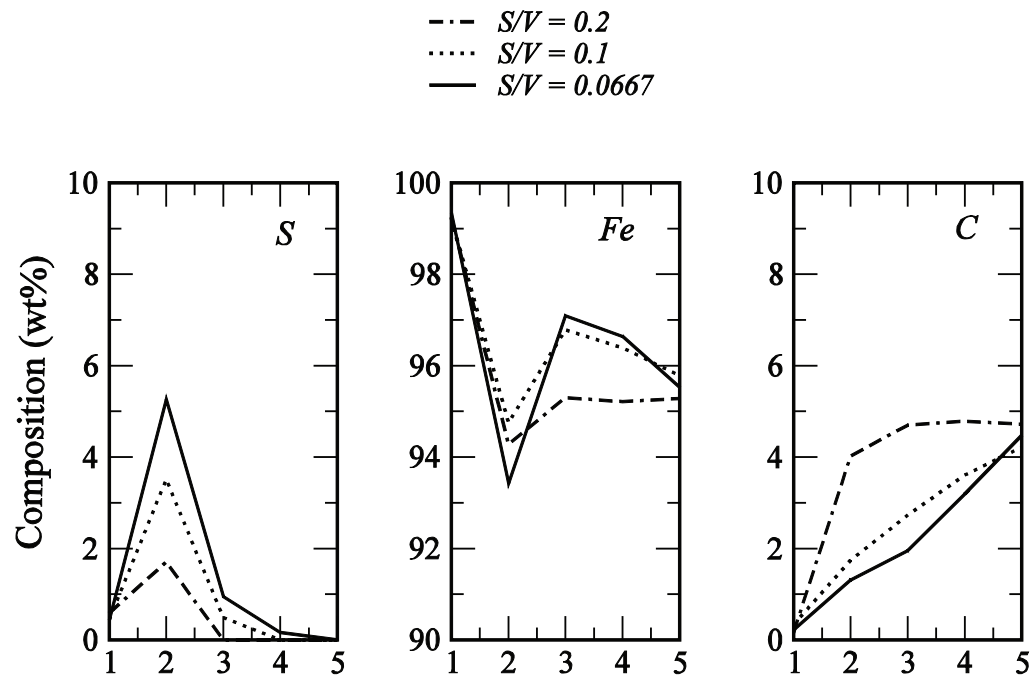

\section{Atomic layers from the surface}

Fig. 12. The effect of surface to volume ratio on the atomic composition profiles in the surface region of liquid bath configuration $(24 \times 24 \times \mathrm{M})$. The depth $\mathrm{M}$ of the bath ranged from 10 to 20 layers for S/V ratios ranging from 0.2 to 0.0667 .

In Fig. 13, we present the influence of S/V ratio in a few extreme scenarios. Very small S/V values were generated by significantly increasing bath depths. Bath depths ranging between 100 and 300 layers for a $24 \times 24$ bath corresponded to S/V ratios between 0.01 and 0.0033 respectively. Sulphur concentrations in the surface region were found to be a strong 
function of S/V ratio. For the lowest $\mathrm{S} / \mathrm{V}$ ratio investigated (0.0033), the sulphur concentration in the $2^{\text {nd }}$ layer showed a sixty fold increase to $30 \mathrm{wt} \%$. Carbon on the other hand was seen to be very low in the surface region. This result indicates that the influence of free surfaces on sulphur redistribution gets significantly reduced with increasing surface areas. For large exposed surfaces, the use of bulk concentrations might provide a reasonable basis for reaction rate computations. Surface active behaviour for sulphur becomes significant for relatively small exposed surfaces and then needs to be appropriately taken into account.

It is important to note that the surface to volume (S/V) ratio has been defined in these simulations as a dimensionless number. For establishing a correspondence between simulation and experimental results and to convert surface/volume ratio in units of $\mathrm{m}^{-1}$, S/V ratios need to be scaled by a factor of $3.10^{9}(=1 / d$, where ' $d$ ' is inter-planar spacing). The simulation results presented above represent systems with large surface to volume ratios, typically observed for micro (or nano)-scale systems, e.g., small liquid droplets. In a macro-scale system, e.g., $(1 \times 1 \times 0.001 \mathrm{~m})$ bath, the $\mathrm{S} / \mathrm{V}$ ratio will be $10^{3} \mathrm{~m}^{-1}$; the number of surface sites will be a small fraction of the total number of atomic sites and the effect of free surfaces will be much reduced.

Deep Molten Bath

$$
\begin{array}{cl}
C=4.2 \mathrm{Wt} \%, & S=0.5 \mathrm{Wt} \%, 1500^{\circ} \mathrm{C} \\
- & \mathrm{S} / \mathrm{V}=0.01 \\
\cdots & \mathrm{S} / \mathrm{V}=0.005 \\
--. & \mathrm{S} / \mathrm{V}=0.0033
\end{array}
$$
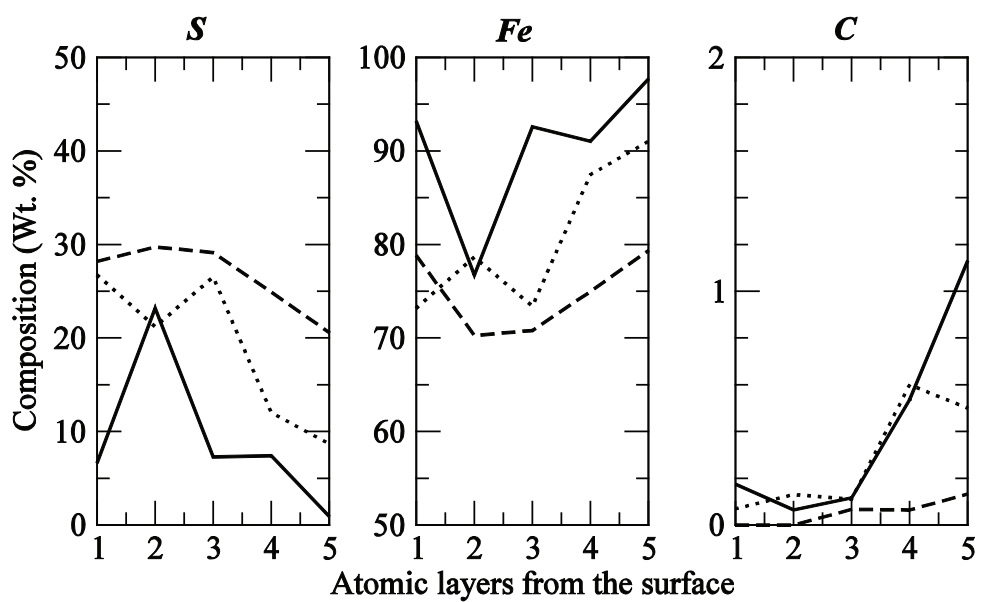

Fig. 13. The effect of surface to volume ratio on the atomic composition profiles in the surface region of liquid bath configuration $(24 \times 24 \times \mathrm{M}) ; \mathrm{C}=4.2 \mathrm{wt} \%, 1500^{\circ} \mathrm{C}$. The depth $\mathrm{M}$ of the bath ranged from 100 to 300 layers for $S / V$ ratios ranging from 0.01 to 0.0033 .

The system was investigated further to probe the influence of temperature and carbon concentration. Temperature was varied from $1400^{\circ} \mathrm{C}$ to $1600^{\circ} \mathrm{C}$, and the carbon 
concentration in the melt from $1.2 \mathrm{wt} \%$ to $5.2 \mathrm{wt} . \%$. Total S was maintained at $0.5 \mathrm{wt} \%(0.025$ at. \%), and the bath configuration had an S/V ratio of 0.0667 . Sulphur was found only in the surface region with very small levels sulphur detected in the bulk region at all temperatures and carbon levels under investigation. Bulk sulphur levels were therefore not reported. In the surface region, there was not much influence of temperature or of carbon concentration on sulphur levels. No well-defined trends could be observed. Carbon levels in the surface region were however significantly lower than the corresponding bulk values. For a $5.2 \mathrm{wt} \%$ $\mathrm{C}$ bulk concentration, the surface region showed $\sim 2 \%$ carbon and the bulk region showed a slightly higher value of $5.6 \mathrm{wt} \%$. Temperature once again had only a marginal influence.

Iron levels in the bulk region were marginally higher than their corresponding levels in the surface region, which was caused by several of the surface sites being preferentially occupied by sulphur atoms. Iron concentration was higher than $94 \%$ across the entire simulation zone. This result indicates that the liquid surface was not completely depleted of iron; iron present in the surface region could participate in a number of surface-based reactions previously considered to be blocked by the sulphur monolayer. There was little influence of temperature. The continuous decrease in iron levels observed with increasing carbon was probably due to overall changes in the bulk metal composition; the presence of free surfaces did not have any role in this decrease.

The influence of sulphur on the re-distribution of carbon within the liquid is an important and novel finding. A high surface accumulation of sulphur automatically resulted in low surface concentrations of carbon. As sulphur was concentrated in the top few layers, the concentration of carbon was significantly reduced in the surface region, and was slightly higher in the bulk region. For $3 \mathrm{wt} \% \mathrm{C}$ in the bulk, $1 \mathrm{wt} \% \mathrm{C}$ was observed in the surface region along with $\sim 3.5 \mathrm{wt} \% \mathrm{C}$ in the bulk region. Surface decarburization and carbon boil phenomena will depend strongly on the carbon concentration in the bulk and in the surface regions. In contrast to the results observed for sulphur, increasing surface areas led to much higher concentrations of carbon closer to the surface, which can be construed as a potential nanoscale effect for liquid steels. Atomic redistribution of carbon caused by the presence of free surfaces could therefore have a significant influence on the operational efficiency of direct ironmaking smelting technologies.

Another key result was finding up to $99 \%$ surface sites being occupied by Fe atoms. Fe-Fe interaction parameters are repulsive in nature with iron being in the molten state at these temperatures. The system tends to lower its energy by concentrating repulsive bonds on free surfaces; both $C$ and $S$ had moved away from the outermost layer. However since $S$ is a surface active element and has a strong attractive interaction with $\mathrm{Fe}, \mathrm{S}$ tended to concentrate in the second layer. Another key finding was on the influence of sulphur on the re-distribution of carbon within the liquid. Carbon and sulphur atoms tend to displace one other in molten steel; a high surface accumulation of sulphur will automatically result in low surface concentrations of carbon. As sulphur was concentrated in the top few layers, the concentration of carbon was significantly reduced in the surface region, and was correspondingly higher in the bulk region. The presence of free surfaces therefore resulted in a major redistribution of various atomic species.

Observed simulation findings are consistent with the formation of iron oxide layer on Fe-C$\mathrm{S}$ droplets in oxidising atmospheres. Iron needs to be a major reacting species present on the surface for oxidising reactions to take place. Secondly, since a major proportion of sulphur 
was present in the second layer and not in the top outermost layer, it would significantly reduce its direct interactions with oxidising gases. This would help minimise loss of sulphur to the environment and could account to a certain extent for the negligible loss of sulphur observed experimentally.

For decarburisation reactions under $\mathrm{CO}_{2}$ atmospheres, the addition of small amounts of sulphur resulted in a significant reduction of decarburization rate. This experimental result was explained by Sain and Belton (1978) by assuming that $S$ atoms blocked most of the surface sites and only $1.4 \%$ active sites were available for other reactions. Based on our simulation results, we suggest an alternative approach. Due to mutual displacement between $C$ and $S$, the presence of $S$ in the surface region would automatically move $C$ away from the surface thereby significantly reducing its direct contact with $\mathrm{CO}_{2}$ gas. The reduction in decarburization rate can also be explained by $\mathrm{C}$ atoms moving away from the surface; a complete blockage of surface by sulphur may not be necessary for slowing down reactions. The results shown in Fig. 11 to 13 have shown sulphur concentrating in the top few layers, with highest sulphur levels being observed in the second layer. Secondly, we have observed that the top layer always contained small amounts of carbon as well. This finding could account for the observed residual decarburisation without the need for arbitrarily blocking reactive sites through atomic misfit or orientation considerations.

Simulation results suggest a novel approach is required to enhance our current understanding on the influence of surface-active elements. Theoretical models using the concept of reactive sites suggest that surface activity effects of sulphur may be due to its occupying a majority of surface sites; a complete coverage of surface with sulphur has been suggested for sulphur levels $\sim 0.07 \mathrm{wt} \%$. Although our results also indicate sulphur concentrating close to the surface, these atoms are present in several top layers instead of a monolayer. Simulations indicate that a complete surface blockage by sulphur is not likely and opens up the possibility for surface reactions with other atomic species such as Fe.

\section{Concluding remarks and future research directions}

\subsection{Key conclusions}

1. Using a rigid graphitic hexagonal lattice, an atomistic model has been developed for the graphite/iron melt interfacial region. This model was validated using the saturation solubility of $\mathrm{C}$ in Fe melts and by the retarding effect of sulphur on $\mathrm{C}$ solubility. A Monte Carlo algorithm was developed using canonical ensemble for investigating the dissolution behaviour of graphite and the reactions taking place at the graphite/melt interface. A contact between graphite and melt led to the dissociation of $C$ atoms from the graphite lattice and their subsequent diffusion in the melt. Some Fe atoms also penetrated the graphite lattice.

2. The rate of mass transfer of $\mathrm{C}$ atoms in the melt was found to be slower than the corresponding dissociation rate at the interface. This led to a build up of $\mathrm{C}$ atoms at the interface. A higher initial $C$ concentration in the melt resulted in a smaller width of the interfacial region. The dissolution of graphite did not take place layer by layer. Instead, a broad interfacial region containing high concentrations of $\mathrm{C}$ and Fe was formed in the top layers of graphite; the initial shape of the dissolving particle remained fairly unchanged over extended periods of contact. 
3. Strong $\mathrm{C}-\mathrm{C}$ bonds in the basal planes of graphite were found to hinder the dissociation of $\mathrm{C}$ atoms from this surface. During the initial stages of contact, interfacial reactions on this interface were very slow and controlled the dissolution process. The dissociation of $\mathrm{C}$ atoms became easier and faster with extended contact. Across prismatic planes, the bonding between $\mathrm{C}$ atoms was very weak and the atoms could be easily dissociated. Interfacial reactions did not play an important role across this interface.

4. An atomistic model was developed for the synthetic graphite-alumina/liquid iron system. An attempt was made to incorporate non-wetting between alumina and graphite through strong but finite repulsion between alumina and iron and also through modifying the nature of interactions on the solid/liquid interface. Both approaches proved to be unsuccessful. A third attempt was then made to simulate the non-wetting behaviour in terms of mutual exclusion of alumina and iron from their immediate neighbourhood. This approach coupled with the immobility of alumina was able to simulate a number of key experimental results on the graphite-alumina/liquid iron system.

5. Alumina interaction parameters were generally found to be redundant having no effect on simulation results. Further simulations were carried out to determine the influence of melt turbulence and temperature on carbon dissolution from synthetic graphitealumina/liquid iron system. While both temperature and melt turbulence had a significant influence on high carbon systems, refractory mixtures containing alumina in excess of $50 \%$ were not affected by increased levels of melt turbulence or higher temperatures. Poor wetting in the interfacial region appears to be the most important factor affecting carbon depletion from refractories.

6. Simulation results have clearly shown that the free surface of molten Fe-C-S can not be approximated to a mono atomic layer. Instead, a surface may be represented by a 3-5 atomic layer thick surface region, where the atomic concentration profiles are significantly different from the bulk liquid. The outermost layer of molten Fe-C-S system was found to be predominantly occupied by Fe atoms; a result that would explain the formation of an iron oxide layer on the liquid surface in oxidising atmospheres. Highest concentration of sulphur atoms in close vicinity to iron atoms in the second layer could account to some extent for the negligible loss of sulphur during the reactions. These experimental results were not previously well explained by the existing theories.

7. The presence of sulphur had a significant influence on the redistribution of carbon in the surface and bulk regions. The carbon concentration in the bulk region was slightly higher than the bulk carbon levels; the surface region on the other hand showed much lower levels of carbon. Increasing surface areas led to much higher concentrations of carbon in the surface region. This result is of great significance for surface decarburization reactions and carbon boil phenomena in direct smelting technologies; the impact of free surface therefore needs to be taken into account for optimizing process efficiencies.

8. The surface-active sulphur was found to concentrate preferentially in the surface region; very little sulphur was found in the bulk region of liquid. With $1.5 \mathrm{wt} \% \mathrm{~S}$ in the bulk melt, $S$ atoms occupied $\sim 30 \%$ sites available on the top surface layer. This result clearly shows that a complete surface coverage with sulphur does not take place even when the number of available sulphur atoms exceeds the number of surface sites 
available. Therefore the ideal monolayer theory, wherein surface-active elements block all the reactive sites on the surface, does not provide an accurate representation of liquid surface in the presence of surface active species.

\subsection{Future research directions}

The characterization of a liquid surface by the missing atomic layers is only a partial representation of surface effects in liquids. Due to surface tension effects, bonds are likely to be stretched along the surface and compressed in a direction normal to the surface. Surface interaction parameters need to be modified and their deviations from bulk interactions determined. These modifications are rather complex and nontrivial in nature, and need to take into account the thickness of the surface layer; the nature, strength and gradients of individual pair potentials. Simulations are currently underway to determine optimum surface interaction parameters and associated surface thermodynamics.

Due to the importance of iron in a number of fields such as magnetism, earth sciences and iron/steel making, a very large number of ' $r$ ' dependent potentials have been reported in the literature that mimic both cohesive and repulsive energetics of materials. Although it is well understood that such models are empirical in nature and fitted to specific material characteristics and applications, these are widely used in atomistic investigations due to their computational efficiency and practical applicability. One of the most widely used schemes is the embedded atom method (EAM) which has been successfully implemented to describe the cohesive properties of metals and the de-cohesive role of impurities such as hydrogen (Daws \& Baskes, 1983). The effects of boundary conditions on the melting process of an ensemble of bcc iron atoms will be investigated by performing the Monte Carlo simulation and using a Lennard-Jones and other distance-dependent pair potentials. The temperature-energy phase diagrams will be used to establish correspondence with iron allotropic transitions. The stability of melting process under fixed wall and free surface condition will be energetically/spatially analysed along with effects of short range order.

We also aim to determine key aspects of surface thermodynamics, bonding network, the influence of surface-active elements, pathways and mechanisms for surface reactions through atomic level investigations on the surface/sub-surface region of molten steel (1550$1650^{\circ} \mathrm{C}$ ). Using a novel approach, key strategic ingredients in the surface reactions of Fe-C-S system, atomic concentration profiles and bonding networks will be determined for the first time with a view to developing a reliable atomistic characterization of the liquid steel surface region. The surface thermodynamical behaviour of molten Fe-C-S system will be determined through computations of surface interaction parameters, free energy and surface tension using an iterative procedure. High temperature experimental measurements will be used to supplement, provide feedback and to validate simulation results. Atomic concentration profiles and reaction pathways will then be determined over a wide concentration/and temperature range followed by a critical analysis and implications for steelmaking reactions.

\section{References}

Binder, K.; Lebowitz, J.L.; Phani, M.K. \& Kalos, M.H. (1981). Monte Carlo study of the phase boundary of binary alloys with face centred cubic structure. Acta Metall., Vol 29, pp. 1655-65. 
Binder, K.; Landau, D.P. \& Ferrenberg, A.M. (1995). Thin Ising films with competing walls: A Monte Carlo study. Phys. Rev. E, Vol. 51, No. 4. Pp. 2823-2838.

Chen, C.; Lin, C \& Chen, S. (2000) Kinetics of synthesis of silican carbide by carbothermal reduction of silicon dioxide. British Ceramic Transactions, Vol 99, No. 2, pp. 57-62.

Chipman, J. (1972), Thermodynamics and the phase diagram for the Fe-C system. Metall. Trans., 1972, Vol. 3, pp. 55-64.

Coller, M.L.F; Sahajwalla, V.; Taylor, I.F. \&Wright, J.K. (1994). Simulation of carbondissolution from non-graphitic sources into iron melts. $6^{\text {th }}$ AUSIMM extractive metallurgy conference, Brisbane. Book Series: Australian Institute of mining and metallurgical publications. Vol. 49, No. 4. pp. 287-294.

Cusack, B.L.; Hardie, G.J. \& Burke, P.D. (1991) HIsmelt - 2nd Generation direct smelting, Second European Ironmaking Conference, Glasgow.

Daw, M.S. \& Baskes, M.I. (1983) Semiempirical, quantum mechanical calculation of hydrogen embrittlement in metals. Phys. Rev. Lett. Vol. 50, pp. 1285-1288.

Ericsson, S.O. \& Melberg, P.O. (1981). Influence of sulphur on the rate of carbon dissolutionIn liquid iron. Scandinavian Journal of Metallurgy. Vol. 10. pp. 15-18.

Gao, K.; Sahajwalla, V.; Sun, H.; Wheatley, C. \& Dry, R. (2000) Influence of sulfur contentand temperature on the carbon boil and CO generation in Fe-C-S drops, ISIJ International, Vol. 40, No. 4, pp. 301-08.

Grigoryan, V.A. \& Karshin, V.P. (1972). Effect of surface-active additives on the kinetics ofdissolution of graphite in liquid iron. Izvest Akad Nauk SssR Metally. Vol. 1, pp. 209-214.

Guillermet, A.F.; Hillert, M.; Jansson, B. \& Sundman, B. (1981). An assessment of the Fe-S system using a two sublattice model for the liquid phase. Metallurgical and Materials Transactions B, Vol.12, pp. 745-754.

Jordan, A.S. (1979). Calculation of Phase Diagrams and Thermochemistry of Alloy Phases (edited by Chang, Y.A. \& Smith, J.F.), The Metallurgical Society of AMIE, New York, 1979, pp. 100-102.

Keogh, J.V.; Hardie, G.J.; Philip, D. K. \& Burke, P.D. (1991). HIsmelt Process Advances to 100,000 t/y plant. Ironmaking Conference Proceedings, ISS-AIME 50, pp. 635-649, Washington DC.

Khanna, R. \& Sahajwalla, V. (1999) Monte Carlo Simulation of Phenomena at Solid Graphite/Fe-C melt Interface, Physica Status Solidi B, Vol. 213, No. 1, pp. 47-58.

Kitchener, J.A.; Bockris, O.M. \& Liberman, D. (1948) The activity of sulphur in liquid iron: the influence of carbon. Faraday Society Discussions, Vol. 4, pp. 49-61.

Kosaka, M. \& Minowa, S. (1968). On the rate of dissolution of carbon into molten Fe-C alloy. Transactions ISIJ. Vol. 8, pp. 392-400.

Lacaze, J. \& Sundman,B. (1991). An assessment of the Fe-C-Si system. Metall and Mater Trans.A, 1991, Vol. 22, pp. 2211-17.

McLean, A. (2006) The science and technology of steelmaking- measurements, models and manufacturing. Metallurgical and Materials Transactions B, Vol. 37B, pp. 319-332.

Mori, T., Fujimura, K. \& Kanoshima, H., (1963) Effects of Aluminium, Sulphur, and Vanadium on the Solubility of Graphite in Liquid Iron, Mem. Fac. Eng.Kyoto Univ., Vol. 25, pp. 83-105. 
Morris J. \& Williams, A. (1949). The effect of silicon on the activity of sulphur in liquid iron. Trans. Amer. Soc. Metals. Vol. 41, pp. 1425-1440.

Moriss, J. \& Buehl, D. (1950) Activity of sulphur in Fe-C alloys. Transactions AIME, Vol. 188, pp. 317-322.

Mourao, M.B.; Murthy, G.G.K. \& Elliot, J.F. (1993). Experimental investigations of dissolution rates of carbonaceous materials in liquid iron-carbon melts. Metallurgical and Materials Trans. Vol. 24 B, pp. 629-638.

Ohtani, H. \& Nishizawa, T. (1986). Calculation of Fe-C-S ternary phase diagram. Trans. ISIJ, Vol. 26, Vol. 9, pp. 655-663.

Olivares, R. (1996). The effect of sulphur on the dissolution of graphites and carbon in liquid iron-carbon alloys. PhD Thesis, University of New Castle, Australia.

Orston, S. \& Oeters, F. (1988). Behaviour of Coal particles blown into liquid iron. W.O. Philbrook Memorial Symposium Proceedings, Iron and Steel Society, Ontario, pp. 27-38.

Roddis, P. G. (1973) Mechanism of decarburisation of iron-carbon alloy drops falling through an oxidising gas. J. Iron Steel Inst., Vol. 211, No. 1, pp.

Sahajwalla, V.; Taylor, I.F.; Wright, J.K. \& Hardie, G.J. (1994) Dissolution of carbon into iron melts- the new direct ironmaking perspective. Metallurgical processes for the early twenty-first century. Vol 1- Basic principles, pp. 715-730.

Sahajwalla, V. \& Khanna R. (1999) Dissolution Behaviour of Particulate Graphite in Fe-C melts: A Monte Carlo Simulation Study, Scand. J of Metallurgy, vol. 29, pp. 114-120.

Sahajwalla, V. \& Khanna, R. (1999). Influence of sulphur on the solubility of graphite in iron melts: a Monte Carlo simulation study, Acta Materialia, Vol. 47, No. 3, pp. 793-800.

Sahajwalla, V. \& Khanna R. (2000) A Monte Carlo simulation Study of Dissolution of Graphite in Iron-Carbon melts, Metallurgical and Materials Trans. Vol. 31 B, pp 15171525.

Sahajwalla, V. \& Khanna R. (2002) Influence of Sulphur on the Solubility of Graphite in FeC-S melts: Optimization of Interaction Parameters, Acta Materiala, Vol. 50, pp 663671.

Sahajwalla, V.; Khanna, R.; Kapilashrami, E. \& Seetharaman, S. (2007) Depletion of carbon from $\mathrm{Al}_{2} \mathrm{O}_{3}-\mathrm{C}$ mixtures into liquid iron: Rate Controlling Mechanisms, Canadian Metallurgical Quarterly, Vol. 46, No. 1, pp. 25-32.

Sain, D.R. \& Belton, G.R. (1976). Interfacial reaction kinetics in the decarburisation of liquid iron by carbon dioxide. Metallurgical and Materials Transactions. Vol. 7, pp. 235-244.

Sain, D.R. \& Belton, G.R. (1978). The influence of sulphur on Interfacial reaction kinetics in the decarburisation of liquid iron by carbon dioxide. Metallurgical and Materials Transactions. Vol. 9, pp. 403-407.

Sasai, K. \& Mizukami,Y. (1995). Improvement of life inversion nozzles with gas injection. ISIJ International. Vol. 35. No. 9, pp. 1072-1078.

Schei,A.; Tuset, J.K. \& Tverit H. (1988), Production of High Silicon Alloys, Tapir Forlaug, Trondheim.

Shpyrko, O.G.;Grigoriev, A.Y.; Streitel, R.; Pontoni ,D.; Pershan, P.S.; Deutsch, M.; Ocko, L.\& Meron M,Lin B. Atomic-Scale Surface Demixing in a Eutectic Liquid BiSn Alloy. Phys. Rev. Lett. 2005; 95: 106103-106107. 
Van Vlack, L.H. (1989). Elements of Materials Science and Engineering, 6th ed., Edison-Wesley Publishing Co., New York, pp. 133-34.

Wright, J.K. \& Taylor, I.F. (1993) Multiparticle Dissolution Kinetics of Carbon in IronCarbon-Sulphur Melts. ISIJ International. Vol. 33, No. 5, pp. 529-538, ISSN: 13475460.

Wu, C.; Wiblen, R. \& Sahajwalla, V. (2000) Influence of ash on mass transfer and interfacial reaction between natural graphite and liquid iron, Metallurgical and Materials Transactions B, Vol. 31B, pp. 1099-1104.

Zhao, L. \& Sahajwalla, V. (2003) Interfacial phenomena during wetting of graphite/alumina mixtures by liquid iron, ISIJ International, Vol. 43, No. 1, pp. 1-6. 


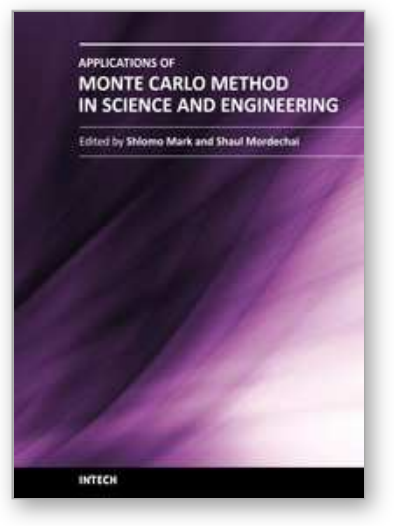

\section{Applications of Monte Carlo Method in Science and Engineering \\ Edited by Prof. Shaul Mordechai}

ISBN 978-953-307-691-1

Hard cover, 950 pages

Publisher InTech

Published online 28, February, 2011

Published in print edition February, 2011

In this book, Applications of Monte Carlo Method in Science and Engineering, we further expose the broad range of applications of Monte Carlo simulation in the fields of Quantum Physics, Statistical Physics, Reliability, Medical Physics, Polycrystalline Materials, Ising Model, Chemistry, Agriculture, Food Processing, X-ray Imaging, Electron Dynamics in Doped Semiconductors, Metallurgy, Remote Sensing and much more diverse topics. The book chapters included in this volume clearly reflect the current scientific importance of Monte Carlo techniques in various fields of research.

\section{How to reference}

In order to correctly reference this scholarly work, feel free to copy and paste the following:

R. Khanna, R. Mahjoub and V. Sahajwalla (2011). Atomistic Monte Carlo Simulations in Steelmaking: High Temperature Carburization and Decarburization of Molten Steel, Applications of Monte Carlo Method in Science and Engineering, Prof. Shaul Mordechai (Ed.), ISBN: 978-953-307-691-1, InTech, Available from: http://www.intechopen.com/books/applications-of-monte-carlo-method-in-science-and-engineering/atomisticmonte-carlo-simulations-in-steelmaking-high-temperature-carburization-and-decarburization-

\section{INTECH}

open science | open minds

\section{InTech Europe}

University Campus STeP Ri

Slavka Krautzeka 83/A

51000 Rijeka, Croatia

Phone: +385 (51) 770447

Fax: +385 (51) 686166

www.intechopen.com

\section{InTech China}

Unit 405, Office Block, Hotel Equatorial Shanghai

No.65, Yan An Road (West), Shanghai, 200040, China

中国上海市延安西路65号上海国际贵都大饭店办公楼 405 单元

Phone: +86-21-62489820

Fax: $+86-21-62489821$ 
(C) 2011 The Author(s). Licensee IntechOpen. This chapter is distributed under the terms of the Creative Commons Attribution-NonCommercialShareAlike-3.0 License, which permits use, distribution and reproduction for non-commercial purposes, provided the original is properly cited and derivative works building on this content are distributed under the same license. 